\title{
Patient Expectations and Experiences of Antidepressant Therapy for Major Depressive Disorder: A Qualitative Study
}

\author{
Bernhard T Baune $\mathbb{D}^{1-3}$ \\ loana Florea $\mathbb{1 D}^{4}$ \\ Bjarke Ebert ${ }^{5}$ \\ Maëlys Touya $\mathbb{D}^{6}$ \\ Anders Ettrup ${ }^{5}$ \\ Monica $\mathrm{Hadi}^{7}$ \\ Hongye Ren (D) $^{8}$ \\ 'Department of Psychiatry and \\ Psychotherapy, University of Münster, \\ Münster, Germany; ${ }^{2}$ Department of \\ Psychiatry, Melbourne Medical School, \\ University of Melbourne, Melbourne, \\ VIC, Australia; ${ }^{3}$ The Florey Institute of \\ Neuroscience and Mental Health, \\ University of Melbourne, Melbourne, \\ VIC, Australia; ${ }^{4}$ Clinical Development, \\ H. Lundbeck A/S, Valby, Denmark; \\ ${ }^{5}$ Medical Strategy \& Communication, \\ H. Lundbeck A/S, Valby, Denmark; ${ }^{6}$ Value \\ Evidence, Lundbeck, Deerfield, IL, USA; \\ ${ }^{7}$ Patient-Centered Research, Evidera, \\ London, UK; ${ }^{8}$ Value Evidence, \\ H. Lundbeck A/S, Valby, Denmark
}

Correspondence: Hongye Ren Email HNRE@lundbeck.com
Purpose: This qualitative study explored patient perceptions of the most burdensome symptoms of major depressive disorder (MDD), the impact of symptoms on patients' daily lives, and patient expectations and experiences regarding the timing of onset of antidepressant pharmacotherapy.

Patients and Methods: Data were collected through facilitated, patient focus-group sessions in the USA between May and June 2019. Participants were adults with confirmed MDD who reported a major depressive episode within the past 2 years, for which they had received pharmacologic treatment for $\geq 6$ weeks. The semi-structured discussion focused on the key topics of bothersome symptoms of MDD, the impact of symptoms on quality of life, and the effects of antidepressant treatment. Interviews were audio-recorded; findings were summarized using a content-analysis approach.

Results: Five focus-group sessions were undertaken, involving a total of 29 patients (each attended one session; mean age, 43.4 years; $72.4 \%$ female). Mean time since confirmed diagnosis of MDD was 13.1 years. The most commonly prescribed antidepressants received were bupropion ( $41.4 \%$ of participants), escitalopram $(34.5 \%)$, and sertraline $(34.5 \%)$. The most frequently reported bothersome MDD symptoms were fatigue (mentioned by $58.6 \%$ of participants), lack of motivation/loss of interest (51.7\%), anxiety/panic (44.8\%), sadness (41.4\%), and lack of concentration/brain fog (41.4\%). Socialization, family life, and work were the areas in which quality of life was most impacted. Participants expressed dissatisfaction with their antidepressant treatment. Fast symptom resolution was mentioned as a priority (defined as $<1$ week by $38.5 \%$ of participants and $\leq 1$ month by $65.4 \%$ ). Most participants had not experienced fast relief from their symptoms with current or previous antidepressant medications.

Conclusion: Results of this qualitative study suggest that fatigue, anhedonia, cognitive symptoms, and anxiety are some of the most bothersome symptoms for patients with MDD and highlight the importance of obtaining rapid relief from these symptoms in order to improve outcomes and patient satisfaction with antidepressant medication.

Keywords: antidepressant therapy, major depressive disorder, onset of treatment effect, patient experience, symptoms, quality of life

\section{Introduction}

Patients with major depressive disorder (MDD) experience a wide range of debilitating symptoms that significantly impair their daily life and functioning, ${ }^{1-3}$ resulting in substantial patient and societal burden. ${ }^{4-6}$ In addition to emotional symptoms (such as depressed mood and anhedonia), patients with MDD may also experience 
cognitive and physical symptoms. ${ }^{7,8}$ The clinical presentation of MDD is known to be highly heterogeneous, with considerable variation among patients in terms of the symptoms experienced. ${ }^{9-12}$

The importance of addressing patient perspectives and priorities when managing mental health disorders is increasingly being recognized. ${ }^{13-16}$ However, it has been shown that patients' perceptions of symptoms and treatment outcomes in MDD often differ from those of their physicians. ${ }^{17-21}$ For example, in a recent online survey, patients with MDD reported experiencing a wider range of symptoms, greater impairment of functioning and different treatment priorities compared with that reported by healthcare providers involved in the treatment of patients with MDD across all phases of the disease. ${ }^{18,20}$ Improved understanding of patients' expectations for antidepressant therapy is required in order to ensure that treatment is meaningful and responsive to their needs. Yet, despite increased recognition of the importance of early optimized therapy in $\mathrm{MDD},{ }^{22-24}$ there is currently no consensus regarding what constitutes a "fast" onset of action of antidepressant therapy for the relief of symptoms of MDD from a patient perspective, or whether patients value fast relief of any particular symptoms over others.

To date, few studies have specifically evaluated patients' lived experiences of MDD symptoms and antidepressant treatment. This paper presents the results of a qualitative investigation undertaken to explore patient perceptions of the most burdensome symptoms of MDD, the impact of those symptoms on patients' daily lives, and patient expectations and experiences regarding the timing of onset of efficacy of antidepressant pharmacotherapy.

\section{Patients and Methods Study Population}

Adults with MDD were recruited through a specialist market-research organization (Global Perspectives, Norwich, UK). Participants were identified via online patient panels (database of patients pre-identified by a third-party recruitment vendor), clinician referrals, patient associations, and social medical advertising and targeting. All potentially eligible participants were screened by telephone by Global Perspectives staff using a standardized recruitment screening script to ensure that the study was presented in a consistent manner and that participants met all pre-specified entry criteria.
Eligible participants were aged 16-65 years at the time of enrollment; reported that they had experienced and recovered from a major depressive episode (MDE) within the past 2 years, for which they received pharmacologic treatment for at least 6 weeks; and were able to read and understand English. Participants were required to provide confirmation of diagnosis and treatment for their recent MDE via either printed medical records or a physician note. The diagnosis was reviewed and confirmed by the study principal investigator or designee. Individuals were excluded from study enrollment if they suffered from mental retardation, an organic mental disorder, or a mental disorder due to a general medical condition according to Diagnostic and Statistical Manual of Mental Disorders $\left(\mathrm{DSM}-5^{\circledR}\right)$ criteria. $^{8}$

\section{Study Design}

This was a qualitative study conducted by Evidera (London, UK and Bethesda, USA). Data were collected by means of facilitated focus-group sessions conducted by scientific staff trained in qualitative research methodology. Five focusgroup sessions, each lasting approximately 120 minutes, were conducted with patients with MDD at two locations in the USA (Dallas, TX and New York, NY). Focus-group sessions were held at clinical sites in private spaces able to accommodate a discussion between up to six participants. Patients each participated in one focus-group session. A moderator was accompanied by a co-moderator who assisted with the focus-group logistics and took detailed notes. A licensed clinical psychologist, contracted by Global Perspectives, was also present during each focusgroup session. The psychologist was introduced to study participants and was available during and after each session for individual consultation, as needed.

In each focus group, the moderator used a semistructured discussion guide focused on the key topics of bothersome symptoms, quality of life, and the treatment participants received for their most recent MDE. Examples of the questions used are shown in Box 1. Most questions were structured to be open-ended to gain insight into the terminology that patients use to describe their lived experience. During the discussion of MDD symptoms, the moderator could probe for more detail on reduced activities and impacts on cognition, functioning, and productivity. Similarly, when discussing MDD treatment, the moderator could enquire for more detail on meaningful changes in treatment and specific symptoms mentioned by participants. 
Box I Examples of Questions Used During the Focus-Group Sessions

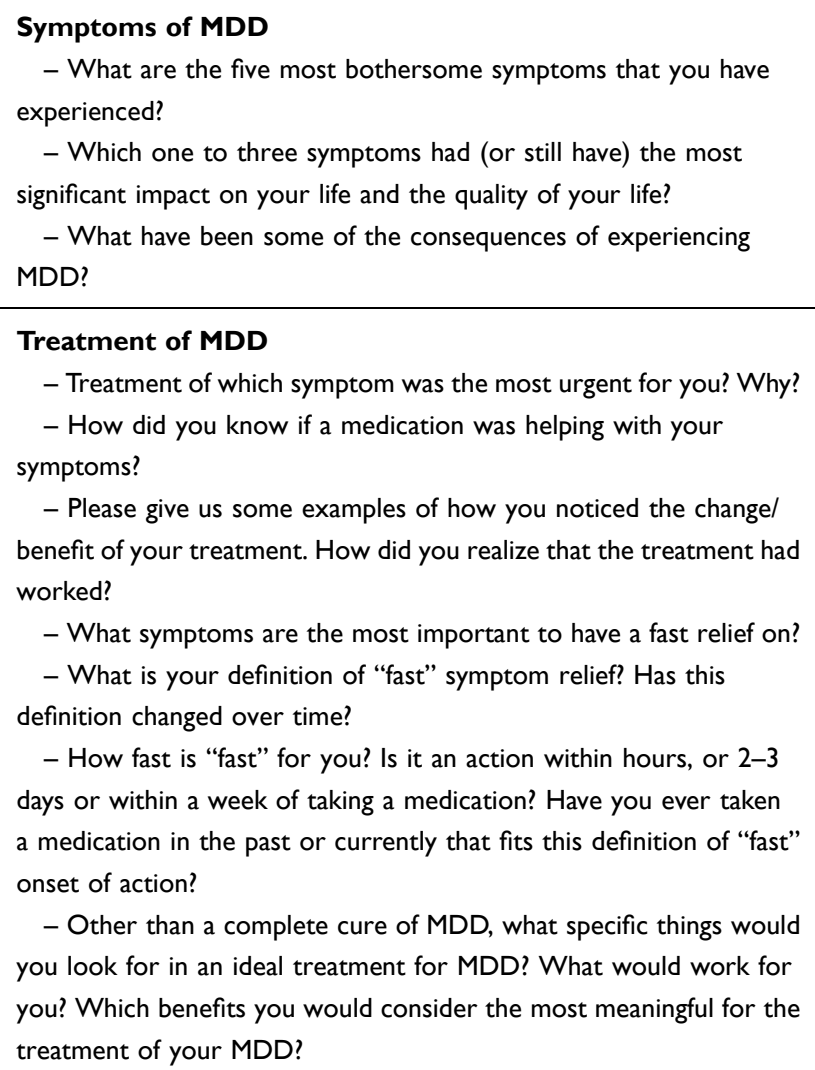

\section{Treatment of MDD}

- Treatment of which symptom was the most urgent for you? Why?

- How did you know if a medication was helping with your symptoms?

- Please give us some examples of how you noticed the change/ benefit of your treatment. How did you realize that the treatment had worked?

- What symptoms are the most important to have a fast relief on?

- What is your definition of "fast" symptom relief? Has this definition changed over time?

- How fast is "fast" for you? Is it an action within hours, or 2-3 days or within a week of taking a medication? Have you ever taken a medication in the past or currently that fits this definition of "fast" onset of action?

- Other than a complete cure of MDD, what specific things would you look for in an ideal treatment for MDD? What would work for you? Which benefits you would consider the most meaningful for the treatment of your MDD?

At the beginning of each focus group, after the study objectives and interview process had been explained, all participants provided written informed consent to participate in the study and for publication of anonymized responses, and oral consent to be audio-recorded. It was made clear to participants that they were free to leave the focus-group session at any time. At the end of the focusgroup discussion, participants completed a clinical and sociodemographic form and were remunerated (each received US\$200 for participation in the study). A protocol was in place for managing participants identified as being at risk of suicide.

The study was conducted in accordance with the ethical principles described in the Declaration of Helsinki. The study and all associated materials were approved by an institutional review board (Advarra IRB, Columbia, MD, USA) before initiation. Following the first two focusgroup sessions, the semi-structured discussion guide underwent moderate revisions to the section regarding treatment goals of MDD. Minor changes were made in order to better elicit responses aligned with the objectives of the study. The modified semi-structured discussion guide was resubmitted to the institutional review board for re-approval before being used in the remaining three focus groups.

\section{Data Abstraction and Analysis}

Interviews were audio-recorded and de-identified content was transcribed verbatim. A content-analysis approach was used to analyze the transcripts and the frequencies of characteristics and attributes were used to summarize content from the focus groups. The qualitative interview data were coded systematically and analyzed thematically using ATLAS.ti (version 8.1; ATLAS.ti Scientific Software Development GmbH, Berlin, Germany), with constant comparison and exploration of deviant cases.

Before the analysis was conducted, a coding dictionary was developed in Microsoft Excel, with the purpose of being able to group and draw comparisons between the focus-group discussions. Two researchers independently coded the transcripts to highlight participant responses to scripted probes, as well as any themes that emerged. The coding process incorporated both concepts anticipated from the study objectives, as well as emergent concepts arising as analysis continued. This initial coding was reviewed by a senior scientific researcher. The senior researcher provided feedback on the coding and reviewed subsequent coding as needed until the coding was consistent between coders.

Coding reports were subject to further analysis, exploring areas of commonality between participants and focus groups. The codes were merged into overarching themes. Participant quotes were grouped and summarized by these themes from the coding dictionary. The characteristics of the survey population were summarized and are reported using descriptive statistics.

\section{Results}

\section{Study Population}

A total of 38 patients with MDD were screened and met the eligibility criteria for focus-group participation $(n=15$ in Dallas and $\mathrm{n}=23$ in New York). Of these, nine patients cancelled or were excluded as they did not provide confirmation of their diagnosis. The remaining 29 patients were interviewed across five focus groups between May and June 2019.

Participants' sociodemographic and clinical characteristics are shown in Table 1 . The mean age was 43.4 years (range, 19-65 years), and participants were predominantly 
Table I Demographic and Clinical Characteristics of FocusGroup Participants

\begin{tabular}{|c|c|}
\hline Characteristic & $\begin{array}{c}\text { Total } \\
(\mathrm{N}=29)\end{array}$ \\
\hline \multicolumn{2}{|l|}{ Age (years) } \\
\hline Mean (SD) & $43.4(13.2)$ \\
\hline \multicolumn{2}{|l|}{ Sex, n (\%) } \\
\hline Female & $21(72.4)$ \\
\hline \multicolumn{2}{|l|}{ Racial background, n (\%) } \\
\hline Black or African American & $6(20.7)$ \\
\hline White & $19(65.5)$ \\
\hline Other $^{\mathrm{a}}$ & $4(13.8)$ \\
\hline \multicolumn{2}{|l|}{ Relationship status, n (\%) } \\
\hline Single/living alone & $14(48.3)$ \\
\hline Married & $4(13.8)$ \\
\hline Partnership/cohabiting & $3(10.3)$ \\
\hline Divorced or separated & $5(17.2)$ \\
\hline Other ${ }^{b}$ & $3(10.3)$ \\
\hline \multicolumn{2}{|l|}{ Employment status, n (\%) } \\
\hline Employed full-time & II (37.9) \\
\hline Employed part-time & $7(24.1)$ \\
\hline Unable to work due to disability & $5(17.2)$ \\
\hline Other ${ }^{c}$ & $6(20.7)$ \\
\hline \multicolumn{2}{|l|}{ Highest level of education, $\mathbf{n}(\%)$} \\
\hline Secondary/high school & I (3.4) \\
\hline Some college/university & $7(24.1)$ \\
\hline College degree & $15(5 \mid .7)$ \\
\hline Postgraduate degree & $3(10.3)$ \\
\hline Other $^{d}$ & $3(10.3)$ \\
\hline \multicolumn{2}{|l|}{ Time since MDD diagnosis (years) } \\
\hline Mean (SD) & I3.I (10.0) \\
\hline Median (range) & $10.8(|-4|)$ \\
\hline \multicolumn{2}{|l|}{ Number of MDD episodes in the past 2 years } \\
\hline Mean (SD) & $4.9(4.6)$ \\
\hline Median (range) & $3(I-20)$ \\
\hline \multicolumn{2}{|l|}{$\begin{array}{l}\text { Comorbidities occurring in } \geq 10 \% \text { of } \\
\text { participants, } \mathbf{n}(\%)^{\mathrm{e}}\end{array}$} \\
\hline Anxiety & $21(72.4)$ \\
\hline Allergies & $13(44.8)$ \\
\hline Chronic pain & $9(31.0)$ \\
\hline High cholesterol & $9(31.0)$ \\
\hline Arthritis & $8(27.6)$ \\
\hline Osteoarthritis & $7(24.1)$ \\
\hline Hypertension & $5(17.2)$ \\
\hline Hyperthyroidism & $5(17.2)$ \\
\hline Asthma & $4(13.8)$ \\
\hline Diabetes mellitus & $4(13.8)$ \\
\hline Cardiovascular & $3(10.3)$ \\
\hline None & $3(10.3)$ \\
\hline
\end{tabular}

(Continued)
Table I (Continued).

\begin{tabular}{|l|c|}
\hline Characteristic & $\begin{array}{c}\text { Total } \\
\mathbf{( N = 2 9 )}\end{array}$ \\
\hline Treatments received by $\geq \mathbf{1 0 \%}$ of participants, & \\
$\mathbf{n}$ (\%) & \\
Bupropion & $12(41.4)$ \\
Escitalopram & $10(34.5)$ \\
Sertraline & $10(34.5)$ \\
Fluoxetine & $7(24.1)$ \\
Venlafaxine & $5(17.2)$ \\
Clonazepam & $5(17.2)$ \\
Trazodone & $4(13.8)$ \\
Quetiapine & $3(10.3)$ \\
\hline
\end{tabular}

Notes: a Other racial background: Asian $(n=1)$, Middle Eastern $(n=1)$, missing $(n=2)$; bother relationship status: living with room-mates $(n=2)$; missing $(n=1)$; ' other employment status: missing/not specified $(n=5)$, retired $(n=1)$; ${ }^{d}$ other highest level of education: missing $(n=3)$; 'other comorbidities: chronic obstructive pulmonary disease/emphysema $(n=2)$, migraine $(n=2)$, hypothyroidism, human immunodeficiency virus, irritable bowel syndrome, kidney disease, lupus, multiple sclerosis, sleep apnea (all $n=I)$; 'other medications: citalopram, duloxetine, desvenlafaxine, alprazolam, aripiprazole (all $n=2$ ), fluvoxamine, paroxetine, zolpidem, gabapentin, lithium, melatonin, mirtazapine, brexpiprazole, topiramate $($ all $n=I)$.

Abbreviations: MDD, major depressive disorder; SD, standard deviation.

female (72.4\%) and white (65.5\%). Most participants were educated to at least college-degree level $(62.1 \%)$ and were employed (full-time, 37.9\%; part-time, 24.1\%). Participants reported having lived with MDD for over 10 years at the time of data collection, with a mean time since MDD diagnosis of 13.1 years (range, $1-41$ years). Participants had experienced a mean of five MDEs within the past 2 years. Most participants reported at least one comorbid medical condition (86.2\%), most commonly anxiety (mentioned by 21 participants $[72.4 \%])$. All participants reported that they were currently receiving treatment for their $\mathrm{MDD}$, most frequently prescription medication ( $82.7 \%$ of all medications reported). The most commonly prescribed antidepressants received within the past 2 years were bupropion (reported by $41.4 \%$ of participants), escitalopram (34.5\%), and sertraline $(34.5 \%)$.

\section{Bothersome Symptoms of MDD}

As shown in Figure 1, a total of 22 unique symptom codes were identified from the focus-group transcripts, encompassing mood, cognitive, and physical symptoms. The three most frequently reported and extensively described symptoms across all focus groups were fatigue (mentioned by $58.6 \%$ of participants), low motivation/loss of interest $(51.7 \%)$, and anxiety/panic (44.8\%). Examples of verbatim quotes used to describe bothersome symptoms of MDD 


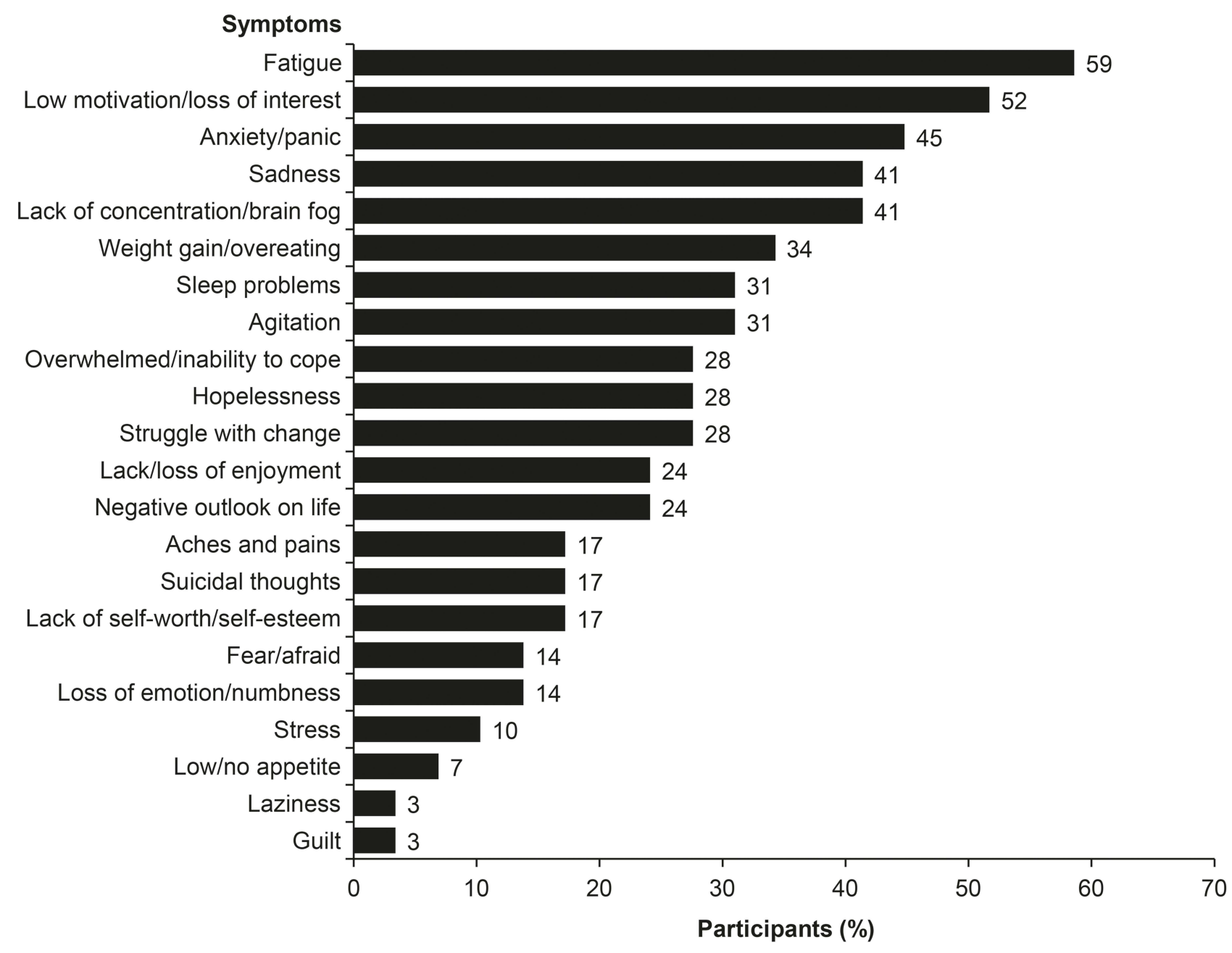

Figure I Proportion of participants reporting each of the 22 unique symptom codes identified from the focus-group transcripts.

reported by the focus-group participants are shown in Table 2.

Many participants expressed feeling fatigued as a result of their MDD. While some mentioned this exact term, others reported "lack of energy," "lethargy," and "tiredness"; for example: "I'm tired all the time. I feel like I have the flu all the time. I just feel achy and tired and just exhausted." Participants reported that during an MDE they were unable to get out of bed and perform routine activities of daily living, maintain close relationships, or meet social engagements. Low motivation was described as "not wanting to do anything" and "lack of interest." Participants mentioned that they lacked the motivation to start or complete activities when depressed, including social activities (most commonly mentioned), maintaining personal hygiene, exercising, paying bills on time, and working productively. Participants commonly reported that lack of motivation had an extensive impact on daily life and was difficult or hard to deal with: "I think the loss of interest in normal activities, the sort of inability to get going, that's quite hard."

Participants commonly reported anxiety. Participants mentioned feeling "anxious all the time," "worried," and "panicky." For some, anxiety was felt in specific situations, whereas others lived with anxiety daily or were aware that it could manifest at any point. Other commonly reported emotions included sadness, agitation and irritability, guilt, fear, and an overall sense of hopelessness. Participants expressed sadness as a feeling of dullness, almost synonymous with being depressed. Lack of concentration or feelings of being in a "fog" or "cloud" were also frequently mentioned. Participants described a lack of concentration and how it impacted upon their lives, with some describing specific effects of cognitive symptoms, such as being unable to focus on things, tending to procrastinate, having racing thoughts, and having 
Table 2 Examples of Verbatim Quotes from Focus-Group Participants Describing Their Symptoms of Major Depressive Disorder

\begin{tabular}{|c|c|}
\hline Symptom & Verbatim Quote(s) \\
\hline Fatigue & $\begin{array}{l}\text { "I get tired very quickly, and I have to push myself." } \\
\text { "The other big thing for me is time with my kids. When I have just this unrelenting exhaustion, it's really hard to be } \\
\text { as involved in their lives as I want to be, and I feel guilty about it." } \\
\text { " ... I don't like to commit to plans sometimes in case I'm going to be too tired or just not feel up for it." }\end{array}$ \\
\hline $\begin{array}{l}\text { Low motivation/loss of } \\
\text { interest }\end{array}$ & $\begin{array}{l}\text { "Yeah, there were weeks, like a period of time where it was like two or three weeks I couldn't leave my bed. } \\
\text { I couldn't leave my bed, didn't shower, didn't brush my teeth." } \\
\text { "Things that I know I need to do, responsibilities, I tend to push them away to the point where I let bills get out of } \\
\text { control. Everything gets out of control and becomes a mess. So it's really hard. It affects every aspect of everything." }\end{array}$ \\
\hline Anxiety & $\begin{array}{l}\text { "I felt like that was part of my life, just feeling that panic, like something horrible was in the middle of happening, and } \\
\text { there was nothing I could do about it." }\end{array}$ \\
\hline Cognitive symptoms & $\begin{array}{l}\text { "I mean, a big one I can think of that I have struggled with for a couple of years now is reading. I used to be a super } \\
\text { big reader. And I have a lot of books, like I keep on buying books that I would love to read, and they just sit on my } \\
\text { bedside table and don't get read." } \\
\text { "It's like a funky fogginess ... I can't think, I can't concentrate. My words end up not even coming out the way that } \\
\text { they should." } \\
\text { "Inability to concentrate. Sometimes when it comes over me, I'm like paralyzed. I can't do anything at all." }\end{array}$ \\
\hline Weight gain/overeating & "During the worst time, I gained a lot of weight, because I emotionally eat." \\
\hline $\begin{array}{l}\text { Sleep problems (mostly } \\
\text { excess sleep) }\end{array}$ & $\begin{array}{l}\text { "I just got to a point where I was cancelling social engagements and stuff because I just wanted to stay in bed and } \\
\text { sleep." } \\
\text { "When I'm depressed I like to sleep a lot. I'll sleep my Saturday away or something and then it's like you feel like } \\
\text { you're missing out on life just sleeping." }\end{array}$ \\
\hline Agitation/irritability & "I get angry and irritable entirely too quickly." \\
\hline $\begin{array}{l}\text { Overwhelmed/inability to } \\
\text { cope }\end{array}$ & $\begin{array}{l}\text { "The feeling of being completely overwhelmed with emotion. It feels like it cripples me so that I can't even } \\
\text { function.” } \\
\text { “Just being able to cope with life. I don't feel like I can cope with anything sometimes. It's just everything } \\
\text { overwhelms me.” }\end{array}$ \\
\hline Hopelessness & $\begin{array}{l}\text { "Feeling hopeless, so I think it's like when you feel depressed like you don't feel like you'll get out of it. Like that's all } \\
\text { you know." }\end{array}$ \\
\hline Lack of enjoyment & “... lack of interest in activities I used to enjoy." \\
\hline Negative outlook & "Pessimism, to where I'm feeling like the world's going to end every little thing that happens." \\
\hline Aches and pains & "I was getting really bad tension headaches ... like really bad painful, stressful, from stress and worry." \\
\hline Suicidal thoughts & $\begin{array}{l}\text { "How about suicidality? That's the top one on my list because I fight Satan every single day to stay alive and that's } \\
\text { been going on since I was } 12 \text {." }\end{array}$ \\
\hline $\begin{array}{l}\text { Lack of self-worth/ } \\
\text { self-esteem }\end{array}$ & “l've always been sad and always feeling like I didn't measure up to other people." \\
\hline Fear & $\begin{array}{l}\text { "One of my main ones [symptoms] was fear. I had a fear of change, fear of dying, fear of failure, fear of success, fear } \\
\text { of being alone, which paralyzed me for years and years and years. It stopped me from being able to accept myself } \\
\text { for who I was." }\end{array}$ \\
\hline Weight loss/low appetite & $\begin{array}{l}\text { "I lost } 30 \text { pounds in two months and I was crying every single day. I'm like something is definitely wrong." } \\
\text { "Eating, my appetite wasn't there, and I knew something was up. I think I lost maybe } 20 \text { pounds or something like } \\
\text { that ..." }\end{array}$ \\
\hline Laziness & “Overeating, tiredness, aches and pains, laziness.” \\
\hline Guilt & “That's [guilt] been a recurring issue for me ... just to the point where I can't function.” \\
\hline
\end{tabular}


Table 3 Areas in Which Patients Felt Their Symptoms of Major Depressive Disorder Had an Impact on Quality of Life

\begin{tabular}{|l|c|}
\hline Description & Participants, n (\%) \\
\hline Family/friends/social life/relationships & $22(75.9)$ \\
Work & $14(48.3)$ \\
Sports and exercise & $11(37.9)$ \\
Hobbies & $7(24.1)$ \\
Chores and errands & $6(20.7)$ \\
Self-medication & $6(20.7)$ \\
Self-care/hygiene & $5(17.2)$ \\
Sex life & $1(3.4)$ \\
\hline
\end{tabular}

a combination of memory problems and lack of concentration. Cognitive symptoms were also reported to have an impact on productivity at work and on the ability to maintain social relationships.

\section{Impact on Quality of Life}

Eight themes were identified encompassing the impact of symptoms of MDD on quality of life (Table 3). Physical impacts included difficulty or struggles with performing routine tasks, such as taking care of personal hygiene needs or cleaning the house. Participants described feeling a loss of control over their lives as a result of their MDD; for example: "I feel like it's in complete control of my day-to-day life. I struggle every day to just do the basic things."

A negative impact of MDD symptoms on social life and relationships was reported by three-quarters of the focus-group participants. Loneliness and isolation were mentioned in a number of different contexts across all focus groups. Participants reported that they did not feel like socializing and were not able to keep to plans, such as visiting friends or family. Others mentioned a profound sense of isolation, not wanting to mingle with strangers, and having little or no desire to make new friends because they felt that they would not be seen as "normal."

Symptoms of MDD were also reported to impact on work life. Participants stated that lack of motivation and fatigue due to MDD made them less focused at work, with some participants reporting that they had either lost a job or were unable to get a well-paying job because of their illness. Several participants described the challenges of being at work and having to put on a "gameface" to get through their day (ie presenteeism); for example:
I feel like sometimes when I'm at work if I'm feeling overwhelmed like I can't show it. It's like I have to wear a mask. You can't really be emotional at work. You have to be performing your duties.

Non-participation in activities previously regarded as being pleasurable or beneficial was a common theme across all five focus groups. In particular, participants reported that symptoms of MDD affected their ability to exercise: "If I'm in one of my depressive episodes, I cannot exercise ... I don't have the motivation to do pretty much anything, and I'll just lie in bed and watch TV." Self-medicating with alcohol or other drugs (often marijuana) to help their MDD symptoms was also mentioned by some participants.

\section{Treatment Experience and Unmet Need}

When asked to describe the most urgent symptoms for which they were seeking treatment, the majority of participants said they wanted relief from feelings of sadness or hopelessness and a sense of anxiety and fear. Other desired outcomes included: feeling less overwhelmed; ability to cope better; improved outlook on life; increased motivation; reduced number of nightmares; reduced "fogginess"; and being social. The majority of participants reported that antidepressant medication made them feel less anxious or calmer, less stressed, better able to cope, and more optimistic. Other improvements included being better able to socialize, being less irritable, and having improved concentration.

Although the treatment benefit of feeling less fatigue was discussed, participants said they did not experience fatigue relief with their medication. In one focus group, all participants agreed that medication did not relieve their fatigue. In addition, some participants reported not experiencing relief from the symptom of sadness, and a few reported experiencing no relief from any of their symptoms while on medication.

When asked to describe how they knew that their MDD medication was effective, participants mentioned experiencing increased motivation; raised productivity; being able to continue with life, more easily complete tasks around the house, and take on more responsibilities; more energy; feeling calmer; and improved concentration. One participant described the positive impact of antidepressant medication as follows: "I'm able to do more at work. I'm able to go out more. I'm able to do what I need to do." 
Table 4 Participants' Perception of What Constitutes "Fast Relief" from Symptoms of Major Depressive Disorder

\begin{tabular}{|l|c|}
\hline Time Period & Participants, $\mathbf{n} \mathbf{( \% )}^{\mathbf{a}}$ \\
\hline$<$ I week & $10(38.5)$ \\
I-2 weeks & $6(23.1)$ \\
2 weeks-I month & $1(3.8)$ \\
I month & $6(23.1)$ \\
$2-3$ months & $3(11.5)$ \\
Missing & $3(-)$ \\
\hline
\end{tabular}

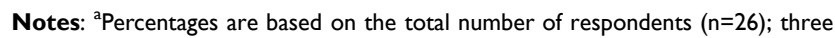
participants did not provide a response.

Participants expressed dissatisfaction with their MDD treatment, focusing on adverse effects of medication. A small number of participants mentioned experiencing weight gain while on antidepressant medication and some were concerned about their medication becoming habitforming. Other adverse effects mentioned by participants included excessive sweating, yawning/drowsiness, and dry mouth.

\section{Speed of Symptom Resolution}

Participants were asked to define "fast relief" in terms of the desired time to relief from symptoms of MDD. Responses varied (Table 4); however, $38.5 \%$ of participants considered fast relief to be less than 1 week. In all, $65.4 \%$ of participants regarded fast relief as being no longer than 1 month and most (88.5\%) considered it to be $<2$ months. Speed of onset was found to be a symptom-contingent perception. Participants considered onset of action within a few minutes to be fast for an anxiety or panic attack; however, for fatigue and general mood symptoms, improvement within a week was perceived to be fast. Most participants felt that they had not experienced fast relief from their symptoms and that symptom relief normally took longer than 1 week. Symptoms for which participants prioritized fast relief included negative outlook, lack of motivation, not wanting to socialize, fatigue, and agitation.

In describing the profile of the ideal antidepressant treatment, participants stated that fast relief of symptoms was the most desired quality. Relief from fatigue was also mentioned as being important. Other desired effects included no longer feeling "foggy," having a more positive outlook, and no longer having symptoms. One participant summed it up as follows:

For me, it would be something that kind of gets me back to the pre-MDD feeling, the way I felt 15-20 years ago where I didn't suffer from it. There weren't these dark places, and I was ambitious. I was motivated. I was a gogetter. I was a lot more social. I wasn't scared about meeting new people. I actually enjoyed meeting new people, and things were a lot easier. And that's what I wish I could get back to.

\section{Discussion}

The results of this study provide valuable insight into patients' lived experiences of the breadth of MDD symptoms and the effects of antidepressant treatment. Study participants appeared to have a history of chronic and sometimes severe MDD as evidenced by disease duration (mean time since diagnosis, 13.1 years), frequency of MDEs (five within the past 2 years), and type of antidepressant received $(41.4 \%$ of participants had received bupropion within the past 2 years). All patients indicated that they were currently receiving treatment for their MDD (most frequently prescription medication, which accounted for $82.7 \%$ of all medications reported). Participants commonly identified the most bothersome symptoms of MDD that disrupted their daily functioning and quality of life as being fatigue, low motivation/loss of interest, anxiety, sadness, and cognitive symptoms. Family/friends/social life/relationships and impact on work were the areas in which quality of life was most impacted by the disease. These findings are consistent with other research that has been conducted into the bothersome symptoms and impact of MDD on the lives of patients. ${ }^{21,25-29}$

Participants expressed feeling dissatisfied with their antidepressant treatment. In particular, they described feeling no relief from fatigue. Fatigue is common in patients with MDD, manifesting across physical, cognitive, and emotional symptom domains and having a significant impact on functioning and quality of life. ${ }^{30}$ Analysis of baseline data from the Sequenced Treatment Alternatives to Relieve Depression (STAR*D) study found fatigue to be the third most common symptom associated with functional impairment in patients with MDD (after sad mood and concentration problems). ${ }^{31}$ In another study, fatigue and lack of energy were among the most common residual symptoms in patients with MDD who were considered to have achieved remission from depressive symptoms. ${ }^{32}$

Consistent with the experience reported by patients in the current study, loss of interest and reactivity to previously pleasurable stimuli (ie anhedonia) is commonly reported in patients with MDD, and is a key diagnostic 
criterion for an $\mathrm{MDE}^{8}$ Anhedonia is a common residual symptom in patients with MDD receiving antidepressant treatment, ${ }^{33}$ and may also be an adverse effect associated with some classes of antidepressants. ${ }^{34-37}$ Recent studies have also shown anhedonia to have a significant impact on functioning in patients with MDD. ${ }^{38-40}$

In line with our findings, cognitive symptoms (eg, disturbances in attention, memory, processing speed, and executive functioning) have also been shown to be a major contributor to disease burden in patients with MDD, and are increasingly being recognized as an important treatment target. ${ }^{41-43}$ Real-world evidence suggests a significant association between patient-reported cognitive symptoms and functional impairment in patients with MDD, ${ }^{2,44-47}$ with improvements in cognitive symptoms predicting overall patient functioning independently of the severity of mood symptoms. ${ }^{45,47}$ The presence of residual cognitive symptoms in patients meeting the criteria for MDD remission has also been shown to be associated with a significantly increased risk of subsequent relapse. ${ }^{48}$

Patients in the present study frequently reported symptoms of anxiety. This is in line with results of other studies, with up to $90 \%$ of patients with MDD also experiencing clinically significant anxiety. ${ }^{25,26,49-52}$ Significant correlation between severity of anxiety symptoms and functional outcomes has been reported in patients with MDD. ${ }^{46,53}$ Anxiety symptoms have also been shown to contribute to poor response to antidepressant treatment in patients with MDD, including lower rates of remission and increased risk of recurrence. ${ }^{49-51,54,55}$

Fast symptom resolution was expressed as a patient priority, although there was considerable variation in the length of time considered to be "fast." In all, 38.5\% of respondents considered "fast" to be less than 1 week and $65.4 \%$ of participants regarded onset of effect within 1 month as "fast relief." Most participants felt that they had not experienced fast relief from their symptoms with current or previous antidepressant medications and mentioned that symptom relief normally took longer than 1 week. The most commonly prescribed antidepressants received by study participants within the past 2 years were bupropion, escitalopram, and sertraline (all reported by over one-third of participants); these antidepressants generally take several weeks to achieve their full therapeutic effects. ${ }^{56}$ These findings suggest a need for antidepressant medications with a more rapid onset of action in order to meet patient expectations.
This study was designed to capture data on the lived experiences of patients with MDD with respect to the types of symptoms experienced, the effects of these symptoms on quality of life, and how these symptoms are impacted by antidepressant medication. Our findings are relevant for both routine clinical practice and research settings. Our results suggest that traditional measures of disease severity in MDD may not fully capture the symptoms and disease impacts most relevant to patients themselves, and provide potential input for the development of novel patient-reported outcomes.

Study limitations include the small sample size (which may not be fully representative of the overall population of patients with MDD encountered in routine practice settings), potential selection bias (for example, individuals who do not feel that their condition is being adequately treated may be more likely to enroll in this type of study), a possible influence of the moderator on group dynamics and answers provided by participants, and the potential influence of participants on each other. Patient experience is also likely to have been influenced by the antidepressant treatment(s) received.

The main strength of this study is that it provides information on the experience of MDD symptoms and effects of antidepressant treatment from the patient's own perspective. Qualitative research methods, such as focusgroup discussions, are an established approach for the evaluation of patients' lived experience and have been widely used across different disease areas. Focus groups enable patients to express their experiences, feelings and expectations in their own words in a supportive environment, promoting the development of shared ideas. In this study, the five focus groups were conducted in two relatively different US locations in order to ensure representativeness of the patients.

\section{Conclusion}

In summary, this qualitative study enhances our understanding of the breadth and importance of symptoms of MDD from the patient perspective and how these burdensome symptoms contribute to diminished quality of life in patients with MDD. Our findings suggest that fatigue, anhedonia, cognitive symptoms, and anxiety have a high priority for patients with MDD and that these are important symptoms for the clinician to recognize and target if patients are to achieve functional recovery. The findings also provide insight into patients' expectations and experiences of antidepressant pharmacotherapy, particularly the 
importance of obtaining rapid relief from symptoms in order to improve patient outcomes and satisfaction with antidepressant medication.

\section{Abbreviations}

MDD, Major depressive disorder; MDE, Major depressive episode.

\section{Data Sharing Statement}

The corresponding author may be contacted for further data sharing.

\section{Ethics Approval}

The study was conducted in accordance with the ethical principles described in the Declaration of Helsinki. The study and all associated materials were reviewed and approved by an institutional review board (Advarra IRB, Columbia, MD, USA) before initiation. All participants provided written informed consent prior to study participation, including consent for publication of anonymized responses.

\section{Acknowledgments}

The authors would like to express their thanks to the focus-group participants for sharing their experiences of MDD and to Sonal Mansukhani of Evidera for her contribution to the design and conduct of the study. The study was conducted by Evidera, funded by $H$. Lundbeck A/S. Editorial assistance was provided by Jennifer Coward and Julie Ponting of Anthemis Consulting, funded by H. Lundbeck A/S.

\section{Author Contributions}

All authors contributed to the conception and design of this study and/or interpretation of data; took part in drafting the article or revising it critically for important intellectual content; agreed to submit to the current journal; gave final approval of the version to be published; and agree to be accountable for all aspects of the work.

\section{Disclosure}

BTB has received speaker/consultation fees from AstraZeneca, Lundbeck, Pfizer, Takeda, Servier, BristolMyers Squibb, Otsuka, LivaNova, and Janssen-Cilag. BTB did not receive financial support from $H$. Lundbeck A/S or other sources for the research presented in this manuscript. IF, BE, AE, and HR are employees of H. Lundbeck A/S. MT is an employee of Lundbeck, USA. MH is an employee of Evidera. The authors report no other conflicts of interest in this work.

\section{References}

1. IsHak WW, James DM, Mirocha J, et al. Patient-reported functioning in major depressive disorder. Ther Adv Chronic Dis. 2016;7 (3):160-169. doi:10.1177/2040622316639769

2. Hammer-Helmich L, Haro JM, Jönsson B, et al. Functional impairment in patients with major depressive disorder: the 2-year PERFORM study. Neuropsychiatr Dis Treat. 2018;14:239-249. doi:10.2147/NDT.S146098

3. Saragoussi D, Christensen MC, Hammer-Helmich L, Rive B, Touya M, Haro JM. Long-term follow-up on health-related quality of life in major depressive disorder: a 2-year European cohort study. Neuropsychiatr Dis Treat. 2018;14:1339-1350. doi:10.2147/NDT. S159276

4. Ferrari AJ, Charlson FJ, Norman RE, et al. Burden of depressive disorders by country, sex, age, and year: findings from the global burden of disease study 2010. PLoS Med. 2013;10(11):e1001547. doi:10.1371/journal.pmed.1001547

5. Greenberg PE, Fournier AA, Sisitsky T, Pike CT, Kessler RC. The economic burden of adults with major depressive disorder in the United States (2005 and 2010). J Clin Psychiatry. 2015;76 (2):155-162. doi:10.4088/JCP.14m09298

6. Friedrich MJ. Depression is the leading cause of disability around the world. JAMA. 2017;317(15):1517. doi:10.1001/jama.2017.3826

7. Kennedy SH. Core symptoms of major depressive disorder: relevance to diagnosis and treatment. Dialogues Clin Neurosci. 2008;10 (3):271-277. doi:10.31887/DCNS.2008.10.3/shkennedy

8. American Psychiatric Association. Diagnostic and Statistical Manual of Mental Disorders. 5th ed. Washington, DC: American Psychiatric Association; 2013.

9. Ostergaard SD, Jensen SO, Bech P. The heterogeneity of the depressive syndrome: when numbers get serious. Acta Psychiatr Scand. 2011;124(6):495-496. doi:10.1111/j.1600-0447.2011.01744.x

10. Fried EI, Nesse RM. Depression is not a consistent syndrome: an investigation of unique symptom patterns in the STAR*D study. J Affect Disord. 2015;172:96-102. doi:10.1016/j.jad.2014.10.010

11. Zimmerman M, Ellison W, Young D, Chelminski I, Dalrymple K. How many different ways do patients meet the diagnostic criteria for major depressive disorder? Compr Psychiatry. 2015;56:29-34. doi:10.1016/j.comppsych.2014.09.007

12. Malgaroli M, Calderon A, Bonanno GA. Networks of major depressive disorder: a systematic review. Clin Psychol Rev. 2021;85:102000. doi:10.1016/j.cpr.2021.102000

13. IsHak WW, Mirocha J, Pi S, et al. Patient-reported outcomes before and after treatment of major depressive disorder. Dialogues Clin Neurosci. 2014;16(2):171-183. doi:10.31887/DCNS.2014.16.2/ rcohen

14. Awad AG. 'The patient': at the center of patient-reported outcomes. Expert Rev Pharmacoecon Outcomes Res. 2015;15(5):729-731. doi:10.1586/14737167.2015.1077118

15. Slade M, Longden E. Empirical evidence about recovery and mental health. BMC Psychiatry. 2015;15:285. doi:10.1186/s12888-0150678-4

16. Loos S, Clarke E, Jordan H, et al. Recovery and decision-making involvement in people with severe mental illness from six countries: a prospective observational study. BMC Psychiatry. 2017;17(1):38. doi:10.1186/s12888-017-1207-4

17. Demyttenaere K, Donneau AF, Albert A, Ansseau M, Constant E, van Heeringen $\mathrm{K}$. What is important in being cured from depression? Discordance between physicians and patients. J Affect Disord. 2015;174:390-396. doi:10.1016/j.jad.2014.12.004 
18. Baune BT, Christensen MC. Differences in perceptions of major depressive disorder symptoms and treatment priorities between patients and health care providers across the acute, post-acute, and remission phases of depression. Front Psychiatry. 2019;10:335. doi:10.3389/fpsyt.2019.00335

19. Mago R, Fagiolini A, Weiller E, Weiss C. Healthcare professionals' perceptions on the emotional impact of having an inadequate response to antidepressant medications: survey and prospective patient audit. Ann Gen Psychiatry. 2018;17:20. doi:10.1186/s12991018-0189-z

20. Christensen MC, Wong CMJ, Baune BT. Symptoms of major depressive disorder and their impact on psychosocial functioning in the different phases of the disease: do the perspectives of patients and healthcare providers differ? Front Psychiatry. 2020;11:280. doi:10.3389/fpsyt.2020.00280

21. Kan K, Jörg F, Buskens E, Schoevers RA, Alma MA. Patients' and clinicians' perspectives on relevant treatment outcomes in depression: qualitative study. BJPsych Open. 2020;6(3):e44. doi:10.1192/ bjo. 2020.27

22. Habert J, Katzman MA, Oluboka OJ, et al. Functional recovery in major depressive disorder: focus on early optimized treatment. Prim Care Companion CNS Disord. 2016;18(5). doi:10.4088/ PCC. 15 r01926

23. Sheehan DV, Nakagome K, Asami Y, Pappadopulos EA, Boucher M. Restoring function in major depressive disorder: a systematic review. J Affect Disord. 2017;215:299-313. doi:10.1016/j.jad.2017.02.029

24. Oluboka OJ, Katzman MA, Habert J, et al. Functional recovery in major depressive disorder: providing early optimal treatment for the individual patient. Int $J$ Neuropsychopharmacol. 2018;21 (2):128-144. doi:10.1093/ijnp/pyx081

25. Kessler RC, Berglund P, Demler O, et al. The epidemiology of major depressive disorder: results from the National Comorbidity Survey Replication (NCS-R). JAMA. 2003;289(23):3095-3105. doi:10.1001/ jama.289.23.3095

26. Kessler RC, Sampson NA, Berglund P, et al. Anxious and non-anxious major depressive disorder in the World Health Organization World Mental Health Surveys. Epidemiol Psychiatr Sci. 2015;24(3):210-226. doi:10.1017/S2045796015000189

27. Battle CL, Uebelacker L, Friedman MA, Cardemil EV, Beevers CG, Miller IW. Treatment goals of depressed outpatients: a qualitative investigation of goals identified by participants in a depression treatment trial. J Psychiatr Pract. 2010;16(6):425-430. doi:10.1097/01. pra.0000390763.57946.93

28. Matza LS, Murray LT, Phillips GA, et al. Qualitative research on fatigue associated with depression: content validity of the Fatigue Associated with Depression Questionnaire (FAsD-V2). Patient. 2015;8(5):433-443. doi:10.1007/s40271-014-0107-7

29. Mannix S, Hassan M, Tummala R, et al. Content validity of the Sheehan Irritability Scale in patients with major depressive disorder. Int Clin Psychopharmacol. 2016;31(2):110-117. doi:10.1097/ YIC.0000000000000113

30. Ghanean H, Ceniti AK, Kennedy SH. Fatigue in patients with major depressive disorder: prevalence, burden and pharmacological approaches to management. CNS Drugs. 2018;32(1):65-74. doi:10.1007/s40263-018-0490-z

31. Fried EI, Nesse RM. The impact of individual depressive symptoms on impairment of psychosocial functioning. PLoS One. 2014;9(2): e90311. doi:10.1371/journal.pone.0090311

32. Conradi HJ, Ormel J, de Jonge P. Presence of individual (residual) symptoms during depressive episodes and periods of remission: a 3-year prospective study. Psychol Med. 2011;41(6):1165-1174. doi:10.1017/S0033291710001911

33. Nierenberg AA. Residual symptoms in depression: prevalence and impact. J Clin Psychiatry. 2015;76(11):e1480. doi:10.4088/ JCP.13097TX1C
34. Price J, Cole V, Goodwin GM. Emotional side-effects of selective serotonin reuptake inhibitors: qualitative study. $\mathrm{Br} J$ Psychiatry. 2009;195(3):211-217. doi:10.1192/bjp.bp.108.051110

35. Sansone RA, Sansone LA. SSRI-induced indifference. Psychiatry. 2010;7(10):14-18.

36. Read J, Cartwright C, Gibson K. Adverse emotional and interpersonal effects reported by 1829 New Zealanders while taking antidepressants. Psychiatry Res. 2014;216(1):67-73. doi:10.1016/j. psychres.2014.01.042

37. Goodwin GM, Price J, De Bodinat C, Laredo J. Emotional blunting with antidepressant treatments: a survey among depressed patients. J Affect Disord. 2017;221:31-35. doi:10.1016/j.jad.2017.05.048

38. Vinckier F, Gourion D, Mouchabac S. Anhedonia predicts poor psychosocial functioning: results from a large cohort of patients treated for major depressive disorder by general practitioners. Eur Psychiatry. 2017;44:1-8. doi:10.1016/j.eurpsy.2017.02.485

39. Cao B, Park C, Subramaniapillai M, et al. The efficacy of vortioxetine on anhedonia in patients with major depressive disorder. Front Psychiatry. 2019;10:17. doi:10.3389/fpsyt.2019.00017

40. McIntyre RS, Loft H, Christensen MC. Efficacy of vortioxetine on anhedonia: results from a pooled analysis of short-term studies in patients with major depressive disorder. Neuropsychiatr Dis Treat. 2021;17:575-585. doi:10.2147/NDT.S296451

41. Lam RW, Kennedy SH, Mclntyre RS, Khullar A. Cognitive dysfunction in major depressive disorder: effects on psychosocial functioning and implications for treatment. Can $J$ Psychiatry. 2014;59 (12):649-654. doi:10.1177/070674371405901206

42. Gonda X, Pompili M, Serafini G, Carvalho AF, Rihmer Z, Dome P. The role of cognitive dysfunction in the symptoms and remission from depression. Ann Gen Psychiatry. 2015;14:27. doi:10.1186/ s12991-015-0068-9

43. Lam RW, McIntosh D; CANMAT Depression Work Group, et al. Canadian Network for Mood and Anxiety Treatments (CANMAT) 2016 clinical guidelines for the management of adults with major depressive disorder: section 1. Disease burden and principles of care. Can J Psychiatry. 2016;61(9):510-523. doi:10.1177/0706743716659416.

44. Chokka P, Bougie J, Rampakakis E, Proulx J. Assessment in Work productivity and the Relationship with Cognitive symptoms (AtWoRC): primary analysis from a Canadian open-label study of vortioxetine in patients with major depressive disorder (MDD). CNS Spectr. 2019;24(3):338-347. doi:10.1017/S1092852918000913

45. Chokka P, Bougie J, Proulx J, Tvistholm AH, Ettrup A. Long-term functioning outcomes are predicted by cognitive symptoms in working patients with major depressive disorder treated with vortioxetine: results from the AtWoRC study. CNS Spectr. 2019;24(6):616-627. doi:10.1017/S1092852919000786

46. Chokka P, Tvistholm AH, Bougie J, Clerzius G, Ettrup A. Improvements in workplace productivity in working patients with major depressive disorder: results from the AtWoRC study. $J$ Occup Environ Med. 2020;62(3):e94-e101. doi:10.1097/JOM.00000 00000001805

47. Haro JM, Hammer-Helmich L, Saragoussi D, Ettrup A, Larsen KG. Patient-reported depression severity and cognitive symptoms as determinants of functioning in patients with major depressive disorder: a secondary analysis of the 2-year prospective PERFORM study. Neuropsychiatr Dis Treat. 2019;15:2313-2323. doi:10.2147/NDT. S206825

48. Saragoussi D, Touya M, Haro JM, et al. Factors associated with failure to achieve remission and with relapse after remission in patients with major depressive disorder in the PERFORM study. Neuropsychiatr Dis Treat. 2017;13:2151-2165. doi:10.2147/NDT. S136343

49. Fava M, Rush AJ, Alpert JE, et al. Difference in treatment outcome in outpatients with anxious versus nonanxious depression: a STAR*D report. Am J Psychiatry. 2008;165(3):342-351. doi:10.1176/appi. ajp. 2007.06111868 
50. Wiethoff K, Bauer M, Baghai TC, et al. Prevalence and treatment outcome in anxious versus nonanxious depression: results from the German Algorithm Project. J Clin Psychiatry. 2010;71 (8):1047-1054. doi:10.4088/JCP.09m05650blu

51. Wu Z, Chen J, Yuan C, et al. Difference in remission in a Chinese population with anxious versus nonanxious treatment-resistant depression: a report of OPERATION study. $J$ Affect Disord. 2013;150(3):834-839. doi:10.1016/j.jad.2013.03.012

52. Yang W, Zhang G, Jia Q, et al. Prevalence and clinical profiles of comorbid anxiety in first episode and drug naive patients with major depressive disorder. J Affect Disord. 2019;257:200-206. doi:10.1016/ j.jad.2019.06.052

53. Chokka P, Ge H, Bougie J, Ettrup A, Clerzius G. Anxiety symptoms in working patients with major depressive disorder treated with vortioxetine: associations with clinical and treatment outcomes in the AtWoRC study. Ther Adv Psychopharmacol. 2021;11:1-11. doi: $10.1177 / 20451253211013148$
54. Saveanu R, Etkin A, Duchemin AM, et al. The international Study to Predict Optimized Treatment in Depression (iSPOT-D): outcomes from the acute phase of antidepressant treatment. J Psychiatr Res. 2015;61:1-12. doi:10.1016/j.jpsychires.2014.12.018

55. Gaspersz R, Nawijn L, Lamers F, Penninx BWJH. Patients with anxious depression: overview of prevalence, pathophysiology and impact on course and treatment outcome. Curr Opin Psychiatry. 2018;31(1):17-25. doi:10.1097/YCO.0000000000000376

56. Machado-Vieira R, Salvadore G, Luckenbaugh DA, Manji HK, Zarate CA Jr. Rapid onset of antidepressant action: a new paradigm in the research and treatment of major depressive disorder. $J$ Clin Psychiatry. 2008;69(6):946-958. doi:10.4088/jcp.v69n061

\section{Publish your work in this journal}

Neuropsychiatric Disease and Treatment is an international, peerreviewed journal of clinical therapeutics and pharmacology focusing on concise rapid reporting of clinical or pre-clinical studies on a range of neuropsychiatric and neurological disorders. This journal is indexed on PubMed Central, the 'PsycINFO' database and CAS, and is the official journal of The International Neuropsychiatric Association (INA). The manuscript management system is completely online and includes a very quick and fair peer-review system, which is all easy to use. Visit http://www.dovepress.com/testimonials.php to read real quotes from published authors. 